\title{
ORDENAMENTO TERRITORIAL E BACIAS HIDROGRÁFICAS: UM ESTUDO SOBRE OS PROJETOS DO COMITÊ PCJ
}

Kleber Andolfato de Oliveira ${ }^{1}$

RESUMO: Tendo como ponto de partida um recorte em torno das bacias hidrográficas, o estudo de ordenamento territorial requer o conhecimento da posição e concepções dos agentes implicados na política de gestão do território. Os sistemas de gestão de recursos hídricos, federal e estadual, adotam a bacia hidrográfica como unidade principal de gerenciamento dos recursos hídricos. Neste quadro, a gestão é partilhada entre poder público e sociedade civil. No caso do Comitê de Bacia PCJ (Piracicaba, Capivari e Jundiaí), uma de suas funções é a definição das regras e critérios para a divisão dos recursos disponíveis para investimentos em torno dos recursos hídricos entre os diferentes proponentes que solicitam recursos. No quadriênio 2004 a 2007, os projetos contemplados mostram com bastante nítida a ênfase atribuída a projetos de implantação de estações de tratamento de água e esgoto e de diminuição de desperdício na rede de distribuição. Para o quadriênio 2008 a 2011, as orientações se voltam para a gestão e educação ambiental sobre o uso dos recursos hídricos da bacia.

Palavras-chave: Plano de bacias; Comitê PCJ; Ordenamento territorial

\section{INTRODUÇÃO}

\footnotetext{
${ }^{1}$ Engenheiro Agrônomo, Mestrando em Ecologia Aplicada pela Escola Superior de Agricultura Luiz de Queiroz (ESALQ/USP). Endereço eletrônico: kadolive@esalq.usp.br
} 


\section{FÓRUM AMBIENTAL DA ALTA PAULISTA}

Atualmente, a gestão dos recursos hídricos nas bacias dos rios Piracicaba, Capivari e Jundiaí (PCJ) é objeto de debates notadamente sobre as políticas públicas que possam contribuir com o ordenamento deste território.

O comitê PCJ nasce na intenção de permitir a participação da sociedade organizada nestes debates. Trata-se de conceber uma gestão na qual aqueles que convivem em determinado meio possam interferir nas escolhas públicas de medidas e ações prioritárias com vistas ao desenvolvimento econômico e social, preservando a qualidade ambiental, notadamente no que se refere à água. Para tanto, o comitê PCJ tem como instrumento Plano de Bacias, que orienta os estudos e projetos que possam melhorar as condições de saneamento, saúde e preservação do ambiente.

Neste trabalho, o conceito de ordenamento territorial é discutido, para em seguida examinar as condições da criação do comitê de bacias PCJ. Enfim, apresenta-se um balanço preliminar dos projetos desenvolvidos no quadriênio 2004-2007 e projetos futuros para o quadriênio 2008-2011 a fim de discutir tendências em torno das evoluções das orientações.

\section{ORDENAMENTO TERRITORIAL}

Conceito muito importante para a geografia, o território diz respeito a uma visão macro do espaço, enfocando grandes conjuntos espaciais (biomas, macrorregiões, redes de cidades, etc.) e espaços de interesse estratégico ou usos especiais (zona de fronteira, unidades de conservação, reservas indígenas, instalações militares, etc.). Interessam aqui as grandes aglomerações populacionais (com suas demandas e impactos) e os fundos territoriais (com suas potencialidades e vulnerabilidades), numa visão de contigüidade que se sobrepõe a qualquer manifestação pontual no território. O conceito contribui com a idéia de captar os grandes padrões de ocupação, as formas predominantes de valorização 
do espaço, os eixos de penetração do povoamento e das inovações técnicas e econômicas e a direção prioritária dos fluxos (demográficos e de produtos) (MORAES, 2005).

No caso do ordenamento territorial, a meta consiste em compatibilizar é a compatibilização de políticas em seus rebatimentos no espaço, evitando conflitos de objetivos e contraposição de diretrizes no uso dos lugares e dos recursos. $O$ ordenamento territorial é um instrumento de articulação transetorial e interinstitucional que objetiva um planejamento integrado e espacializado da ação do poder público.

Ordenar o território implica em analisar questões que envolvem 0 desenvolvimento socioeconômico equilibrado das regiões, a melhora da qualidade de vida, a gestão responsável dos recursos naturais e a utilização racional do território (SANTOS, 2005).

Neste pensamento, o estudo de ordenamento territorial no caso da gestão das bacias hidrográficas requer uma reflexão sobre as posições e articulação dos agentes envolvidos, sobre os dispositivos de políticas públicas e sobre a história da ocupação territorial. Neste estudo, o Comitê de Bacias dos rios Piracicaba, Capivari e Jundiaí constitui um fórum pertinente para obter elementos de reflexão sobre o as políticas com vocação de ordenamento territorial.

\section{CRIAÇÃO DO COMITÊ PCJ}

O modelo de desenvolvimento industrial do início do século XX privilegiou o uso da água para fins de produção de energia elétrica. Na década de, 80 , com a transição democrática brasileira, iniciou-se um processo de discussão e participação da sociedade na gestão de recursos naturais, mesmo que ainda incipiente. Neste período, a questão da água era focada nas necessidades dos usuários deste recurso e as políticas publicas existentes eram relacionados ao combate das secas e inundações, deixando de lado a análise dos impactos 
ambientais ocasionados pela má utilização/manutenção do recurso e das obras hidráulicas.

Com a constatação da degradação dos rios e mananciais de abastecimento, a sociedade passou a questionar a atuação do governo no gerenciamento dos recursos naturais, a exigir mecanismos de participação e controle mais eficazes e a cobrar a implementação de políticas públicas de gerenciamento integrado dos recursos hídricos (COMITÊS PCJ, 2009).

De fato, já em 1976, era criado o Comitê do Alto Tietê, que tinha como objetivo melhorar as condições sanitárias das Bacias do Rio Tietê e Cubatão, notoriamente os cursos d'água mais poluídos e degradados do estado de São Paulo. No ano de 1978, ainda foi criado o Comitê Especial de Estudos Integrados de Bacias Hidrográficas (CEEIBH), tendo como proposta promover o uso racional dos recursos hídricos de domínio federal.

Em 1991, São Paulo instituiu a Política Estadual de Recursos Hídricos, com princípios e diretrizes para atualização periódica do Plano Estadual de Recursos. A lei que instituiu a Política Estadual de Recursos Hídricos informa também a composição do Conselho Estadual de Recursos Hídricos $(\mathrm{CRH})$, com a participação de representantes de Secretarias de Estado, dos municípios e de entidades da sociedade civil relacionadas às áreas de recursos hídricos, bem como cria mecanismos financeiros necessários à implementação dos planos de bacias e ao suporte dos comitês e do próprio sistema, através do Fundo Estadual de Recursos Hídricos (FEHIDRO).

Com o propósito de melhorar a utilização dos recursos hídricos, um movimento em favor do modelo francês de gerenciamento de comitê de bacia hidrográfica se desenvolve em São Paulo e no Rio Grande do Sul. Neste modelo, todas as camadas da sociedade são envolvidas e participam do fórum de discussão. A partir dessa mobilização foi homologada a Lei $\mathrm{N} .{ }^{\circ}$ 9.433, de 8 de janeiro de 1997, mais conhecida como a Lei das Águas, que institui no Brasil os Comitês de Bacias Hidrográficas como forma de gerenciamento dos recursos 
hídricos e o Sistema Nacional de Gerenciamento de Recursos Hídricos (COMITÊS PCJ, 2009).

Esta política tem como base os seguintes fundamentos: a definição da bacia hidrográfica como unidade de planejamento; o reconhecimento da água como um bem finito e vulnerável e de seus usos múltiplos (o que, por conseqüência, quebra a hegemonia do setor elétrico sobre os demais usuários); e a atribuição de valor econômico da à água. Nesta última perspectiva, tal valoração é julgada como indutora do uso racional desse bem natural, o que leva à instituição da cobrança pela utilização dos recursos hídricos e a uma gestão descentralizada e participativa (poderes públicos, usuários e comunidades).

Os comitês são colegiados compostos por representantes de municípios (prefeitos), de órgãos estaduais e de entidades representativas da sociedade civil (ONGs, universidades, associações) com uma concepção de paridade visando uma intenção de partilhar direitos e o poder de deliberar na tomada de decisões. Nesta medida, os comitês de bacia são considerados "o parlamento das águas". Eles possuem atribuições de promover o debate sobre questões relacionadas aos recursos hídricos da bacia, articular e integrar a atuação das entidades que trabalham com este tema, resolver conflitos relacionados a esses recursos naturais, aprovar e acompanhar a execução do Plano de Recursos Hídricos da Bacia; estabelecer os mecanismos de cobrança pelo uso dos recursos hídricos e sugerir os valores a serem cobrados; estabelecer critérios e promover a divisão dos custos das obras de uso múltiplo, de interesse comum ou coletivo (COMITÊS PCJ, 2009).

Em 1989, antes mesmo da promulgação da política paulista de recursos hídricos, é criado o Consórcio Intermunicipal das Bacias dos Rios Piracicaba e Capivari, movimento independente sustentado financeiramente com a contribuição das prefeituras dessas bacias hidrográficas. $O$ decreto 34.530 de 30 de dezembro de 1991 aprova a criação do grupo de trabalho entre o Estado e o Consórcio Intermunicipal das Bacias dos rios Piracicaba e Capivari, para estudar e propor 
formas de atuação integrada, além de um programa de financiamento junto a agentes internacionais e ao governo federal.

A primeira fase dos trabalhos deste grupo se constituiu na realização de inúmeras reuniões, com diferentes agentes envolvidos. Tratou-se de: Divulgar a Lei 7.663, colher subsídios para os trabalhos de confecção da minuta de Estado do Plano de Bacias Hidrográficas, além de realizar e-reuniões mais amplas, com a participação de representantes da sociedade civil. É dessa forma que foram sendo gradativamente construídos os primeiros artigos da minuta do Estatuto do CBH-PCJ. Num primeiro momento, a própria equipe base efetuou 0 aperfeiçoamento da minuta elaborada e, num segundo momento, os municípios, o Consórcio Intermunicipal, Estado e a sociedade civil foram também envolvidos.

Em 18 de novembro de 1993, o Comitê de Bacias do Piracicaba, Capivari e Jundiaí foi instalado na Câmara Municipal de Piracicaba, com a cerimônia de posse de seus membros e eleição, pelos mesmos, do Presidente, Vice-Presidente e do Secretário Executivo. Por unanimidade, foram aprovados, seu estatuto, o Plano de Bacias e a proposta de criação da Agência de Bacia.

\subsection{OS PROJETOS DESENVOLVIDOS E PROJETOS FUTUROS}

No caso do Comitê PCJ, a Secretaria Executiva é responsável por operacionalizar os recursos do Fehidro (Fundo Estadual de Recursos Hídricos) e a Agência de Água PCJ se incumbe pelos recursos originários da Cobrança pelo Uso da Água em rios de domínio da União. Esses recursos financeiros devem ser destinados à gestão dos recursos hídricos, projetos, serviços e/ou obras, reembolsáveis ou a fundo perdido, desde que os mesmos estejam de acordo com os critérios técnicos estabelecidos e aprovados no âmbito dos Comitês PCJ (Federal e Estaduais).

Para a divisão dos recursos, os Comitês PCJ devem seguir as diretrizes descritas no Plano Estadual de Recursos Hídricos (PERH), instrumento definido 


\section{FÓRUM AMBIENTAL DA ALTA PAULISTA}

na Política Estadual de Recursos Hídricos. Como mencionado acima, os Comitês de Bacias elaboram seus os Planos, cuja finalidade é realizar diagnósticos e prognósticos de seus recursos hídricos, apontando as soluções específicas que cada Comitê deve adotar de modo a resolver os principais problemas locais.

Instrumento de gestão quadrienal, o Plano de Bacias Hidrográficas estabelece as metas de curto, médio e longo prazo a partir dos diagnósticos de situação

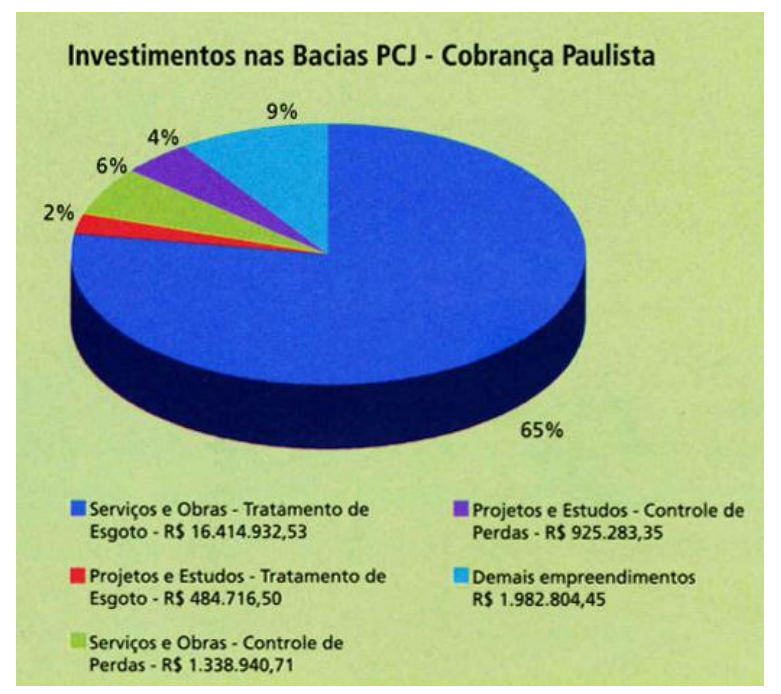

Figura 01 - Investimentos realizados no quadriênio 2004-2007, cobrança paulista (Comitês PCJ).

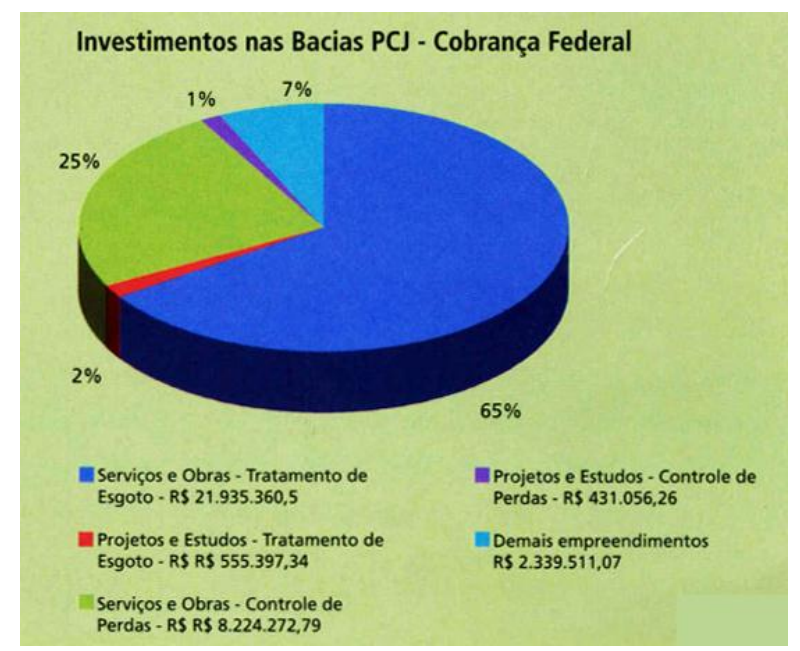




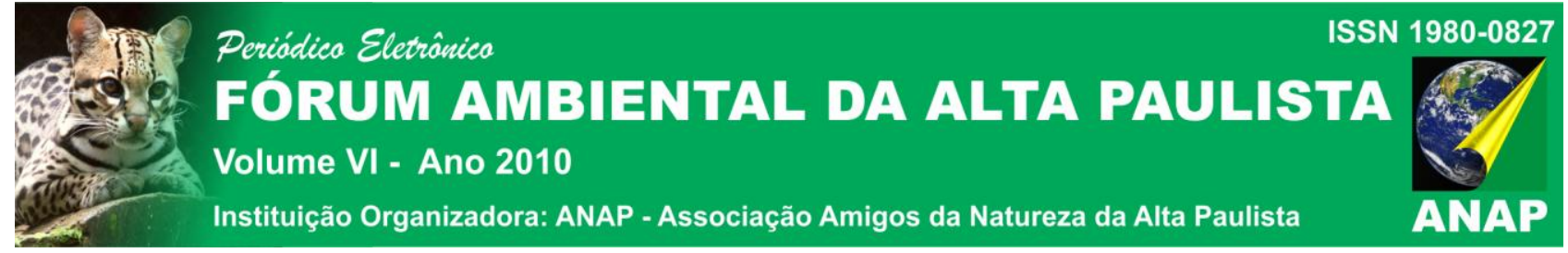

Figura 02- Investimentos realizados no quadriênio 2004-2007, cobrança federal (Comitês PCJ)

Analisando os projetos contemplados no quadriênio de 2004 a 2007, torna-se bastante nítida a ênfase dada a projetos de Tratamento de água e esgoto e controle de perdas (Figuras 1 e 2). Porém, outros projetos também foram atendidos como por exemplo aqueles que visam a criação de base de dados, cadastros, estudos e levantamentos, aqueles de Conservação e Proteção dos Corpos D'água, de Promoção e Uso Racional dos Recursos Hídricos, de Aproveitamento Múltiplo dos Recursos Hídricos, de Prevenção e Defesa Contra Eventos Hidrológicos Extremos e também projetos de Capacitação Técnica, Educação Ambiental e Comunicação Social (IRRIGART, 2007).

Para o quadriênio 2008 a 2011, os programas de investimento se orientam por uma linha de gestão e educação dos recursos hídricos, tais como água limpa, recuperação de matas ciliares, proteção aos mananciais do consórcio PCJ e conservador das águas. Tal grupo de projetos é efetivamente inscrito num rol de medidas e intervenções que podem ser examinadas pela perspectiva do ordenamento territorial (STS, 2008).

\section{CONCLUSÕES}

Os esforços para a manutenção e preservação do ecossistema parece ser a linha de frente dos futuros projetos do Comitê PCJ. É de extrema importância que os olhares sobre o rural $e$ as possibilidades das multifunções entrem em consonância com as intenções do comitê.

Fica claro que o ordenamento territorial acontece em consonância com o andamento dos debates e dos programas desenvolvidos pelo Comitê de Bacias, uma vez que o mesmo atua pensando nas melhorias da Bacia e do desenvolvimento preservando o ambiente com olhar para a sociedade e para 
economia, isso implica em uma maior participação social nos debates acerca dos rumos que os municípios e os empreendimentos na região segue.

\section{REFERÊNCIAS}

COMITÊS PCJ. Comitês das Bacias Hidrográficas dos Rios Piracicaba, Capivari e Jundiaí. Histórico do CBH-PCJ. Arquivos Institucionais do Comitê PCJ, on line. Disponível em: [http://www.comitepcj.sp.gov.br/comitespcj.htm]. Acesso em: 15 de junho de 2009.

IRRIGART, Engenharia e Consultoria em Recursos Hídricos. Bacias hidrográficas dos rios Piracicaba, Capivari e Jundiaí : situação dos recursos hídricos 2004/2006. Relatório síntese. Coordenação de Ricardo Petrine Signoretti; Adriana Marchiori Silva... [et al.]. Piracicaba: FEHIDRO/PCJ/CBJ-PCJ, 2007. 75 p.

MORAES, Antonio C.R. Ordenamento territorial: uma Conceituação para o Planejamento Estratégico. in: Para pensar uma política nacional de ordenamento territorial : Anais da Oficina sobre a Política Nacional de Ordenamento Territorial, Brasília, 13-14 de novembro de 2003. Ministério da Integração Nacional, Secretaria de Políticas de Desenvolvimento Regional (SDR). - Brasília: MI, 2005. $78 \mathrm{p}$.

SANTOS, Thereza C. Algumas Considerações Preliminares sobre o Ordenamento Territorial in: Para pensar uma política nacional de ordenamento territorial : Anais da Oficina sobre a Política Nacional de Ordenamento Territorial, Brasília, 1314 de novembro de 2003. Ministério da Integração Nacional, Secretaria de Políticas de Desenvolvimento Regional (SDR). - Brasília: MI, 2005. 78 p. 
STS, Engenharia Ltda. Plano das Bacias Higrográficas dos Rios Pircacicaba, Capivari e Jundiaí, 2008-2011. Publicação on line. Disponível em:

[http://www.comitepcj.sp.gov.br/comitespcj.htm]. Piracicaba: FEHIDRO/PCJ/CBJPCJ, 2008. 